\title{
ОФТАПЬМОПОГИЯ OPHTALMOLOGY
}

DOI: 10.29413/ABS.2018-3.1.12

УДК 617.7-089:616-089

Опещенко И.Г. ', Забопотский Д.В. 2, Юрьева Т.Н. 1, 3, Сенченко Н.Я. ', Шантурова М.А. ${ }^{1}$

\section{ПРОТИВОВОСПАЛИТЕЛЬНОЕ ДЕЙСТВИЕ КРЫЛОНЁБНОЙ БЛОКАДЫ В ОФТАЛЬМОХИРУРГИИ}

\footnotetext{
1 Иркутский филиал ФГАУ МНТК «Микрохирургия глаза» имени акад. С.Н. Фёдорова» Минздрава России (664033, г. Иркутск, ул. Лермонтова, 337, Россия)

${ }^{2}$ ФГБОУ ВО “Санкт-Петербургский государственный педиатрический медицинский университет” Минздрава России

(194100, г. Санкт-Петербург, ул. Литовская, 2, Россия) ${ }^{3}$ Иркутская государственная медицинская академия последипломного образования - филиал ФГБОУ ДПО «Российская медицинская академия непрерывного профессионального образования» Минздрава России (664049, г. Иркутск, Юбилейный, 100, Россия)
}

\begin{abstract}
Несмотря на значительный прогресс в результативности и безопасности современной факоэмульсификации, на сегодняшний день сохраняются риски развития операционных и послеоперационных осложнений, возникновения воспалительного процесса на фоне физиологической гиперреактивности детского организма на хирургическую травму.

Современная офтальмохирургия предъявляет определённые требования к анестезии, кроме того, задачей современной анестезии является создание продлённого ноцицептивного блока как в интра-, так и в послеоперационном периоде методом одной инъекции, что особенно важно при неконтролируемом поведении ребёнка.

Цель: оценить эффективность анальгетического и противовоспалительного действия крылонёбной блокады при хирургическом лечении катаракты у детей.

Материалы и методы. Проведён сравнительный анализ эффективности интраоперационной анестезии и течения послеоперационного периода у 52 пациентов двух клинических групп, сформированных в зависимости от метода обезболивания. В первую клиническую группу включены пациенты, которым в качестве регионарного компонента общей анестезии выполняли крылонёбную блокаду, вторая клиническая группа группа сравнения - сформирована из пациентов, которым выполнялась ретробульбарная блокада.

Для оценки адекватности анестезии определяли концентрацию кортизола плазмы крови и окислительновосстановительного профиля до и после операции, интенсивность болевого синдрома, проводили оценку степени воспалительной реакции глаза после оперативного вмешательства.

Результаты показали снижение концентрации кортизола и нарастание антиоксидантной способности организма после операции у пациентов первой группь.

У пациентов первой клинической группы феномен Тиндаля I степени выявили в 15,3 \% случаев, у остальных пациентов признаков воспаления не было. У каждого второго пациента второй группы присутствовала умеренная степень воспалительной реакции, а в 7 \% случаев отмечены значительные явления экссудативного характера в виде феномена Тиндаля II степени.

Выводы. Использование крылонёбной блокады как компонента сочетанной анестезии при хирургическом лечении катаракты позволило улучшить качество реабилитации пациента с врождённой катарактой как в ранний, так и в поздний послеоперационный период.

Ключевые слова: крылонёбная блокада, окислительно-восстановительный потенциал, врождённая катаракта
\end{abstract}

\section{ANTI-INFLAMMATORY EFFECT OF PTERYGOPALATINE BLOCKADE FOR ANESTHETIZATION IN OPHTHALMIC SURGERY}

Oleshchenko I.G. ', Zabolotskiy D.V. ${ }^{2}$, Yureva T.N. ${ }^{1,}{ }^{2}$, Senchenko N.Ya. ${ }^{1}$, Shanturova M.A. ${ }^{1}$

\author{
${ }^{1}$ Irkutsk Branch of S. Fyodorov Eye Microsurgery Federal State Institution \\ (ul. Lermontova 337, Irkutsk 664033, Russian Federation) \\ ${ }_{2}^{2}$ Saint Petersburg State Pediatric Medical University \\ (ul. Litovskaya 2, Saint Petersburg 194100, Russian Federation) \\ ${ }^{3}$ Irkutsk State Medical Academy of Postgraduate Education - \\ Branch Campus of the Russian Medical Academy of Continuing Professional Education \\ (Yubileyniy 100, Irkutsk 664049, Russian Federation)
}

Purpose: to evaluate the effectiveness of analgesic and anti-inflammatory effects of pterygopalatine blockade in the surgical treatment of cataract in children.

Materials and methods. A comparative analysis of the efficacy of intraoperative anesthesia and the course of the postoperative period was carried out in 52 patients of two clinical groups that were formed depending on the method of anesthesia. The first clinical group included 26 patients who underwent a pterygopalatine blockade as a regional component of general 
anesthesia, the second comparison group was formed of 28 patients undergoing retrobulbar blockade. To assess the adequacy of anesthesia, the concentration of plasma cortisol and oxidation-reduction profile was determined before and after the operation, the intensity of the pain syndrome, the extent of the inflammatory reaction of the eye after surgery were assessed. The results showed a decrease in the concentration of cortisol and increased antioxidant capacity of the organism after surgery in patients of the first group.

In patients of the $1^{\text {st }}$ clinical group, the Tyndal phenomenon of the $1^{\text {st }}$ degree was revealed in $15.3 \%$ of cases, the remaining patients had no signs of inflammation. Each second patient of $2^{\text {nd }}$ group had a moderate degree of inflammatory reaction, and in $7 \%$ of cases significant exudative phenomena were noted in the form of the Tyndall II degree phenomenon. Conclusion. The use of vesicle blockade in the surgical treatment of cataracts allowed improving the quality of rehabilitation of a patient with congenital cataract, both in the early and late postoperative period.

Key words: pterygopalatine blockade, oxidation-reduction potential, congenital cataract

Врождённая катаракта по-прежнему занимает лидирующие позиции среди причин слепоты и слабовидения у пациентов детского возраста [4] (рис. 1). По данным разных авторов, детская инвалидность при помутнении хрусталика достигает 9,4-37,3%, что приводит к социальной дезадаптации ребёнка и снижению качества его жизни. Врождённые катаракты являются устранимой причиной слепоты и подлежат хирургическому удалению, однако позднее хирургическое лечение этого заболевания, неадекватная коррекция афакии, отсутствие активного плеоптического лечения после операции способствуют формированию тяжёлых необратимых нарушений зрительного восприятия у маленьких пациентов [5].

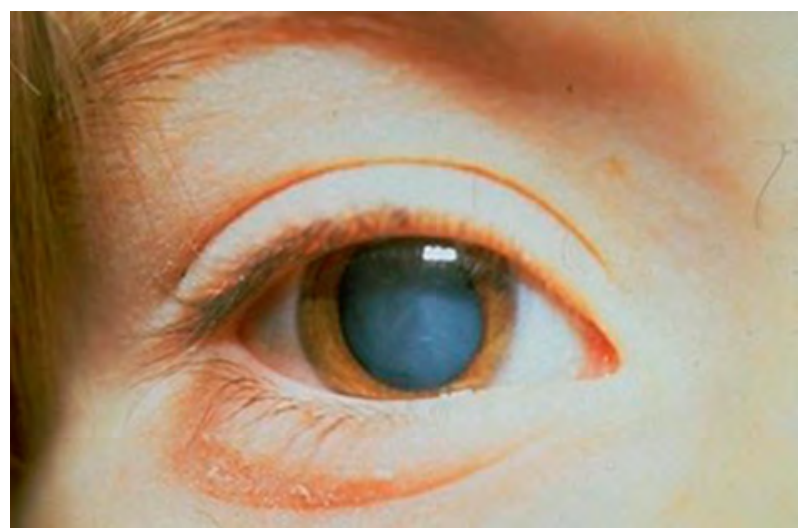

Рис. 1. Врождённая катаракта.

Fig. 1. Congenital cataract.

Несмотря на большой полиморфизм, все клинические формы врождённых катаракт характеризуются отсутствием плотного ядра хрусталика, прочностью связочного аппарата, низкой вязкостью стекловидного тела, наличием витреолентикулярных сращений, частым сочетанием катаракты с различными аномалиями переднего и заднего отделов глаза, что требует иной, по сравнению с возрастными патологиями, хирургической тактики $[15,18]$.

Базовые принципы хирургии врождённых катаракт в детском возрасте разработаны в начале 2000-х гг., и их высокая эффективность доказана на большом числе наблюдений ведущими мировыми офтальмологами (Xottersirom Ch., Tasstgnon M. Vanavada A., Kugelberg М.). К числу данных принципов относят: лимбальный доступ; малый тоннельный разрез (2,2-2,75 мм); использование вискоэластиков; передний капсулорексис; тщательную факоэмульсификацию - факоаспирацию-ирригацию содержимого капсулярного мешка; эндокапсулярную имплантацию гибких моноблочных интраокулярных линз (ИОЛ). Кроме того, вскрытие задней капсулы в случаях её помутнения рекомендовано производить под предварительно имплантированной ИОЛ, а эффективные процедуры передней витрэктомии способствуют поддержанию чёткой визуальной оси.

Несмотря на значительный прогресс в результативности и безопасности современной факоэмульсификации, на сегодняшний день сохраняются риски развития операционных и послеоперационных осложнений, риски возникновения воспалительного процесса на фоне физиологической гиперреактивности детского организма на хирургическую травму $[6,12]$. Наиболее распространённым осложнением хирургии катаракты у детей является формирование вторичной катаракты в поздний послеоперационный период, который, по данным различных авторов, развивается в 33-85 \% случаев (рис. 2).

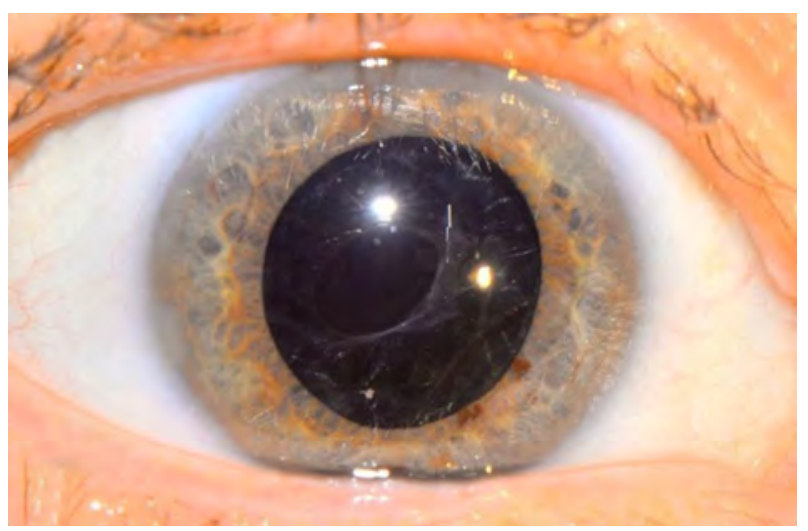

Рис. 2. Вторичная катаракта.

Fig. 2. Secondary cataract.

Современная офтальмохирургия предъявляет определённые требования к анестезии - это создание условий для работы хирурга, обеспечивающих нормальный офтальмотонус для проведения адекватной факоаспирации и имплантации интраокулярной линзы [3]. Кроме того, задачей современной анестезии является создание продлённого ноцицептивного блока как в интра- , так и в послеоперационном периоде методом одной инъекции, что особенно важно при неконтролируемом поведении ребёнка [2].

\section{ЦЕЛЬ ИССЛЕДОВАНИЯ}

Оценить эффективность анальгетического и противовоспалительного действия крылонёбной блокады при хирургическом лечении катаракты у детей. 


\section{МАТЕРИАЛЫ И МЕТОДЫ}

В проспективное нерандомизированное исследование включены 52 ребёнка в возрасте 7,8 $\pm 2,9$ лет, прооперированных в плановом порядке в ФГАУ МНТК «Микрохирургия глаза» им. акад. С.Н. Фёдорова» Минздрава России за период с 01.01.2014 по 01.01.2016 гг. по поводу врождённой катаракты.

Критерии включения:

- согласие родителей или законного представителя пациента на проведение исследования;

- возраст от 5 до 15 лет;

- плановые офтальмологические операции по поводу врождённой катаракты;

- оценка прогнозируемого оперативного риска по шкале NARCO SS до 5 баллов.

Критерии исключения:

- отказ родителей или законного представителя пациента от проведения исследования;

- наличие противопоказаний для проведения регионарных блокад;

- нарушение протокола исследования.

Был проведён сравнительный анализ эффективности интраоперационной анестезии и течения послеоперационного периода у пациентов двух клинических групп, которые были сформированы в зависимости от метода обезболивания.

В первую клиническую группу $(n=26)$ были включены пациенты, которым в качестве регионарного компонента выполняли крылонёбную блокаду на фоне ингаляционной анестезии севофлюраном; вторая клиническая группа $(n=28)$ - группа сравнения сформирована из 28 пациентов, которым выполнялась ретробульбарная блокада.

Для оценки адекватности анестезии определяли концентрацию кортизола плазмы крови до и после операции иммуноферментным методом на аппарате «Bio-tek Instruments Inc. Elx 800» (США) [14]. Для оценки окислительно-восстановительного статуса до и после операции был рассчитан коэффициент соотношения FORT (Free Oxygen Radicals Testing), представляющий собой суммарный показатель свободных радикалов к показателю FORD (Free Oxygen Radicals Defence) суммарной концентрации антиоксидантов. Интенсивность болевого синдрома после операции оценивали по пятибалльной шкале вербальных оценок (ШВО). Кроме того, проводили оценку комфортности выполнения оперативного вмешательства хирургом: «удовлетворительно» (отсутствие трудностей), «неудовлетворительно» (трудности выполнения дозированного капсулорексиса, измельчение передней камеры, смещение иридохрусталиковой диафрагмы, перфорация капсулы, выпадение стекловидного тела). Учитывали время выполнения оперативного вмешательства. Проводили оценку степени воспалительной реакции глаза на первые сутки после операции. С помощью бинокулярного микроскопа со специальным вмонтированным источником света (щелевая лампа), применяя метод проходящего освещения, определяли наличие или отсутствие корнеального синдрома, отёка роговицы и степень выраженности феномена Тиндаля. Корнеальный синдром включал в себя 3 показателя: светобоязнь, слезотечение, блефароспазм, - отражая степень раздражения чувствительных нервных окончаний роговицы. В отдалённые сроки наблюдений оценивалась частота возникновения вторичной катаракты. Средний период наблюдения составил 18 месяцев.

Статистический анализ проводили с помощью пакета программ Statistica 6.0. Проверку нормальности распределения полученных данных выполняли с использованием критерия Шапиро -Уилкса. Данные представлены в виде среднего значения (M), стандартного отклонения (SD), медианы (Me), первого (Q1) и третьего квартиля (Q3). Для оценки различия средних в несвязанных выборках применяли критерий Манна - Уитни, в связанных выборках - критерий Вилкоксона.

\section{РЕЗУЛЬТАТЫ}

У пациентов обеих групп в ходе операции наблюдалась гемодинамическая стабильность, показатели САД, ДАД и СрАД не имели статистически значимых различий $(p>0,05)$.

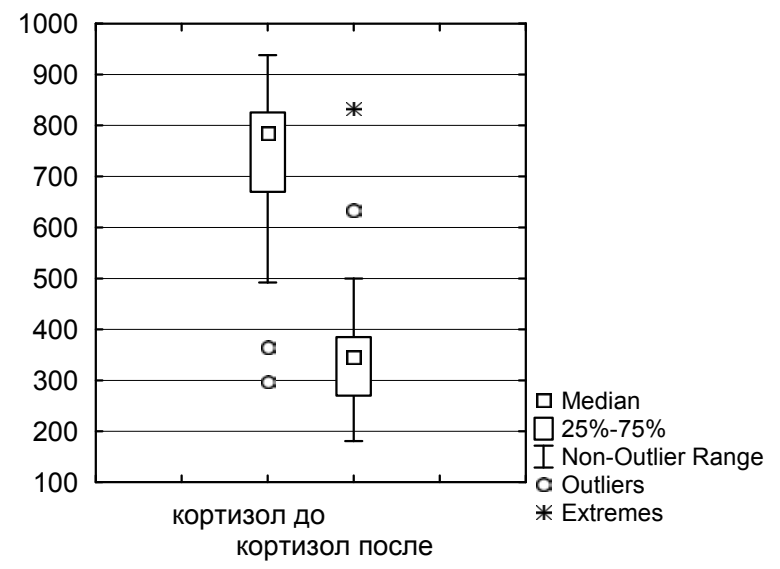

a

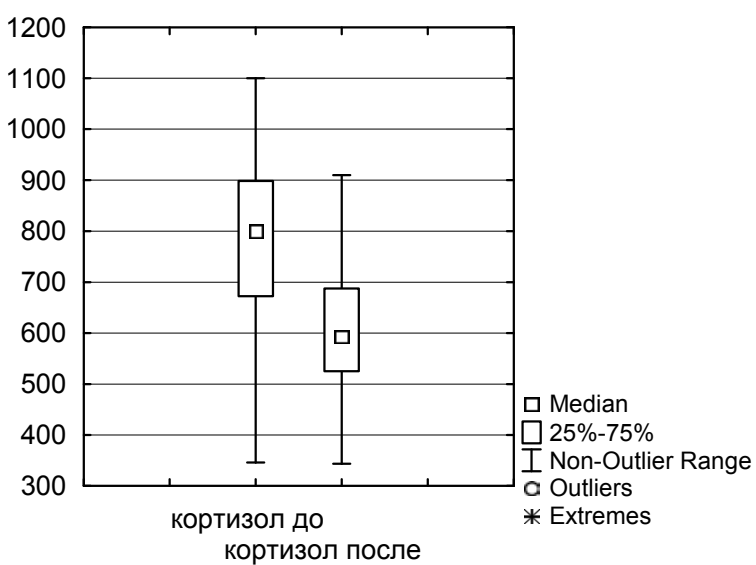

б

Pис. 3. Динамика показателей кортизола в крови у детей до и после оперативного вмешательства в группах (Ме (Q1; Q3)). а -первая клиническая группа (регионарный компонент - крылонёбная блокада); б - группа сравнения (регионарный компонент - ретробульбарная блокада).

Fig. 3. Dynamics of cortisol level in blood before and after operation. (Me (Q1; Q3)): a - $1^{\text {st }}$ clinical group (regional component - pterygopalatine blockade); $\sigma-2^{\text {nd }}$ group of comparison (regional component - retrobulbare blockade). 
Сравнительный анализ уменьшения концентрации кортизола в сыворотке крови до и после операции у пациентов обеих групп продемонстрировал статистически статистическую разницу у детей первой клинической группы, где как вид регионарной анестезии была выполнена крылонёбная блокада. Уровень кортизола был на 25 \% ниже, чем в группе сравнения (рис. 3).

Динамика изменения окислительно-восстановительного статуса до и после оперативного вмешательства в сторону нарастания антиоксидантной способности организма была отмечена у пациентов 1-й клинической группы, где данный коэффициент вырос на $45 \%$ в то же время у пациентов группы сравнения изменения данного показателя не произошло (табл. 1).

Таблица 1

Изменение окислительно-восстановительного коэффициента до и после оперативного лечения

Table 1

Change in the oxidation-rehabilitation coefficient before and after the surgery

\begin{tabular}{|l|c|c|}
\hline $\begin{array}{c}\text { Окислительно- } \\
\text { восстановительный } \\
\text { коэффрициент }\end{array}$ & $\begin{array}{c}\text { 1-я группа } \\
(\boldsymbol{n}=\mathbf{2 6})\end{array}$ & $\begin{array}{c}\text { 2-я группа } \\
(\boldsymbol{n}=\mathbf{2 8})\end{array}$ \\
\hline До операции & $0,44 \pm 0,13$ & $0,46 \pm 0,31$ \\
\hline После операции & $0,64 \pm 0,02$ & $0,46 \pm 0,1$ \\
\hline$p^{*}$ & $<0,05$ & $>0,05$ \\
\hline
\end{tabular}

Примечание. * - для статистического анализа использован критерий Манна - Уитни.

Уровень боли при его оценке по шкале вербальных ощущений через 2 часа после операции не имел статистически значимых отличий у пациентов обеих групп. При анализе динамики изменения интенсивности боли после оперативного лечения было характерно более значительное уменьшение болевого синдрома через 8 часов. В первой клинической группе средний уровень боли был в 4 раза меньше, по сравнению со второй группой, где в качестве компонента регионарной анестезии использовалась ретробульбарная блокада (рис. 4).

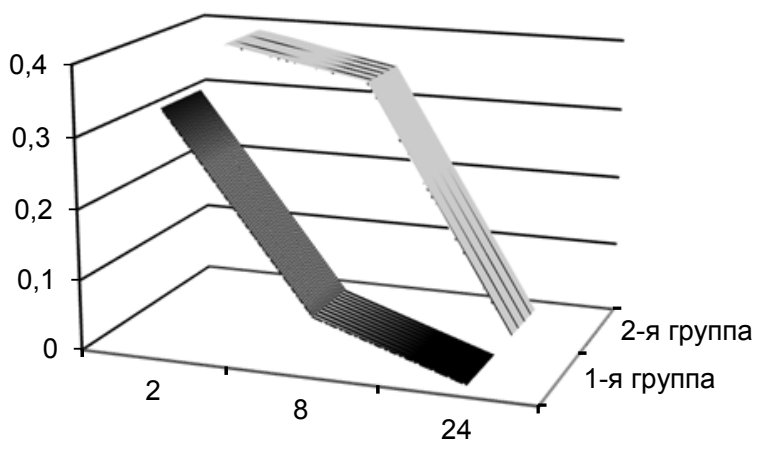

Рис. 4. Динамика интенсивности болевого синдрома.

Fig. 4. Dynamics of the pain syndrome intensity.

При оценке хирургом комфортности выполнения оперативного вмешательства отмечено, что в 1-й клинической группе 12 \% вмешательств были оце- нены как неудовлетворительные, когда как в группе сравнения трудности выполнения дозированного капсулорексиса, измельчение передней камеры, смещение иридохрусталиковой диафрагмы, перфорация капсулы, выпадение стекловидного тела были зарегистрированы в 67 \% случаев.

Длительность хирургического вмешательства также имела статистически значимые отличия $(p<0,05):$ в первой клинической группе среднее время составило 19,6 \pm 7,4 минуты, в группе сравнения $32,5 \pm 16,2$ минуты.

Важно отметить, что разные виды регионарной блокады определяли и различную степень местной воспалительной реакции (табл. 2).

Таблица 2

Оценка офтальмологического статуса в первые сутки после операции в группах

Table 2

Assessment of ophthalmic status in groups during the first 24 hours in a postoperative period

\begin{tabular}{|l|c|c|c|}
\hline $\begin{array}{c}\text { № } \\
\text { группы, } \boldsymbol{n}\end{array}$ & $\begin{array}{c}\text { Отек } \\
\text { роговицы, } \\
\boldsymbol{n}(\%)\end{array}$ & $\begin{array}{c}\text { Феномен } \\
\text { Тиндаля, } \\
\boldsymbol{n}(\%)\end{array}$ & $\begin{array}{c}\text { Корнеальный } \\
\text { синдром І-ІІ степени, } \\
\boldsymbol{n}(\%)\end{array}$ \\
\hline $\begin{array}{l}\text { 1-я группа, } \\
n=26\end{array}$ & $5(19,2 \%)$ & $4(15,3 \%)$ & $2(7,6 \%)$ \\
\hline $\begin{array}{l}2-я \text { группа, } \\
n=28\end{array}$ & $9(32,1 \%)$ & $18(64,2 \%)$ & $9(32,1 \%)$ \\
\hline
\end{tabular}

Наличие корнеального синдрома у пациентов 1-й группы было отмечено в 7,6 \% случаев, а во 2-й группе светобоязнь и блефороспазм наблюдались у $32,1 \%$ пациентов.

У пациентов 1-й клинической группы феномен Тиндаля І степени выявили в 15,3 \% случаев, у остальных пациентов признаков воспаления не было.У каждого второго пациента 2-й группы присутствовала умеренная степень воспалительной реакции, а в 7 \% случаев отмечены значительные явления экссудативного характера в виде феномена Тиндаля II степени.

Оценка взаимосвязи между двумя независимыми качественными признаками, такими, как вид регионарной анестезии и наличие феномена Тиндаля, отражающего уровень воспалительной реакции после операции, с помощью коэффициента $\chi^{2}$ Пирсона показала статистически значимую взаимосвязь между ними, коэффициент равен $0,45(p<0,01)$.

В отдалённом послеоперационном периоде, составившем 18 месяцев после хирургического лечения катаракты, выявлено, что вторичная катаракта в 1-й клинической группе возникла у 11,5 \% прооперированных больных, а в группе сравнения - в 2 раза чаще, что потребовало выполнения последующей лазерной дисцизии ретролентального фиброза (табл. 3).

Таблица
Частота возникновения вторичной катаракты
и доля выполнения лазерной дисцизии Table 3

The incidence of secondary cataract and the proportion of laser discission

\begin{tabular}{|l|c|c|}
\hline & 1-я группа & 2-я группа \\
\hline $\begin{array}{l}\text { Всего операций по поводу } \\
\text { врожденной катаракты }(n)\end{array}$ & 26 & 28 \\
\hline Доля лазерной дисцизий $(\%)$ & $11,5 \%$ & $21,4 \%$ \\
\hline
\end{tabular}




\section{ОБСУЖДЕНИЕ}

Уникальность блокады крылонёбного ганглия обусловлена его расположением в специфическом анатомическом месте, его строением и связью с более высокими центрами мозга [10]. Крылонёбный узел представлен симпатическими, парасимпатическими и чувствительными волокнами, что является основой для нескольких механизмов действия блокады: 1) прерывание постганглионарного парасимпатического пути с целью подавления боли и головных вегетативных симптомов [13]; 2) прерывание модуляции ноцицептивного потока, что обеспечивает обезболивание структур, имеющих отношение к глазу, орбите и орбитальной клетчатке за счёт периферических чувствительных анастомозов II ветви тройничного нерва с цилиарным узлом [11]; 3) блок симпатической опосредованной боли вследствие прерывания постганглионарного симпатического оттока [17].

Полученные результаты показывают, что крылонёбная блокада в качестве регионарного компонента анестезии при хирургии врождённой катаракты у детей не только имеет существенный обезболивающий эффект в периоде оперативного вмешательства, но и обладает эффектом пролонгированного обезболивания до 24 часов после операции. Кроме того, полученные данные указывают на то, что блокада структур крылонёбного ганглия участвует в ограничении неспецифических реакций организма на хирургическую травму, о чём свидетельствует снижение уровня кортизола в крови и повышение уровня антиоксидантной активности у пациентов, которым в качестве регионарного компонента была выбрана крылонёбная блокада [19].

Известно, что кортизол играет наиболее значимую роль в ответе организма на хирургическую травму, и его уровень является адекватным отображением качества проводимого обезболивания. Снижение уровня кортизола в 1-й группе на $25 \%$, по сравнению со 2-й группой, позволяет говорить об эффективности блокады афферентных импульсов из области операционного вмешательства.

Стресс-индуцированные метаболические сдвиги, развивающиеся по типу оксидативного стресса, приводят к усилению процессов пероксидации липидов, нарушению липидных структур клеток, истощению антиоксидантной системы и потенцированию синдрома эндогенной интоксикации [9].

Окислительно-восстановительный коэффициент, который можно использовать для прогностического критерия возникновения оксилительного стресса и вероятности возникновения ранних воспалительных осложнений на фоне ограничения стресс-реакции, вызванной хирургическим вмешательством, в наших исследованиях изменился только в 1-й группе, где блокада, помимо прерывания афферентного ноцицептивного потока обеспечивала вегетативный блок. Влияние на состояние оксидативного равновесия важно для прерывания каскада патобиохимических реакций, снижения риска гиперальгезии, повышенной чувствительности сенсорных нервных окончаний к действию медиаторов боли. Высокий уровень антиоксидантной активности обеспечивает устойчивость к перекисным повреждениям клеточных мембран. В зависимости от силы оксидативного стресса клеточная мембрана нарушается и содержимое клетки высвобождается, что в результате может повредить окружающие клетки и ткани усилением эндотелиальной дисфункции, возникновением синдрома капилляро-трофической недостаточности и воспаления [7].

Наши результаты согласуются с работами C.H. Boone (2017), где определена роль блокады в снижении синтеза токсических метаболитов кислорода, подавлении продукции простагландинов и лейкотриенов, увеличении локального синтеза простациклина [8].

Активация перекисного окисления липидов с накоплением продуктов свободно-радикального окисления обладает повреждающим действием на биологические мембраны клетки. В результате происходит повреждение важнейших регуляторных механизмов клеток, в том числе и лейкоцитов: нарушаются рецепторная и транспортная функции мембран, контактные свойства клеточных поверхностей и, что самое важное, межклеточные взаимодействия.

Антиоксидативная и антиноцицептивная эффективность крылонёбной блокады согласуется с положительной динамикой клинических показателей (офтальмологический статус).

Можно предположить, что снижение оксидативного стресса и продлённое ноцицептивное действие крылонёбной блокады привело к ограничению выраженности послеоперационных воспалительных процессов. Феномен Тиндаля (степень которого зависит от количества лейкоцитов и других воспалительных элементов во влаге передней камеры глаза и отёка конъюнктивы) был менее выражен у больных 1-й группы.

В последние годы в литературе особое время уделяется проблеме вторичной катаракты у детей и ретролентального фиброза, несмотря на успехи современной микрохирургической техники [1].

Выполнение первичного заднего капсулорексиса и передней витрэктомии является компонентами стандартной педиатрической хирургии катаракты: это устраняет субстрат для разрастания LEC (эпителиальных клеток хрусталика) и минимизирует помутнение визуальной оси. Однако эти дополнительные манипуляции и выбор современных (ареактивных) моделей интраокулярных линз не исключают полностью возможности возникновения вторичной катаракты [16].

Практически двукратное снижение частоты возникновения вторичной катаракты у пациентов с крылонёбной блокадой можно объяснить существующим противовоспалительным действием блокады в раннем послеоперационном периоде, что предотвращает выраженность экссудативных реакций, которые и являются морфологическим субстратом ретролентального фиброза.

\section{выводы}

Использование крылонёбной блокады как компонента сочетанной анестезии при хирургическом 
лечении катаракты позволило снизить выраженность хирургического стресса в ходе оперативного вмешательства, улучшить качество реабилитации пациентов с врождённой катарактой как в раннем, так и в позднем послеоперационном периоде, что привело к улучшению зрительных функций.

\section{Финансирование}

Исследование не имело спонсорской поддержки. Конфликт интересов

Авторы заявляют об отсутствии конфликтов интересов.

\section{ЛИТЕРАТУРА REFERENCES}

1. Боброва Н.Ф., Хмарук А.Н. Закономерности помутнения задней капсулы хрусталика после факоаспирации различных форм врожденных катаракт у детей различного возраста // Вестник ОГУ. - 2004. № S. - C. 70-72.

Bobrova NF, Khmaruk AN. (2004). Patterns of clouding of the posterior capsule of the lens after phacoaspiration of various forms of congenital cataracts in children of different ages [Zakonomernosti pomutneniya zadney kapsuly khrustalika posle fakoaspiratsii razlichnykh form vrozhdennykh katarakt u detey razlichnogo vozrasta]. Vestnik Orenburgskogo gosudarstvennogo universiteta, (S), 70-72.

2. Заболотский Д.В., Корячкин В.А. Ребенок и регионарная анестезия - зачем? куда? и как? // Регионарная анестезия и лечение острой боли. - 2016. № 4 . - C. 243-253.

Zabolotskiy DV, Koryachkin VA. (2016). Child and regional anesthesia - why? where? and how? [Rebenok i regionarnaya anesteziya - zachem? kuda? i kak?]. Regionarnaya anesteziya i lechenie ostroy boli, (4), 243-253.

3. Олещенко И.Г., Юрьева Т.Н., Заболотский Д.В., Горбачев В.И. Блокада крылонебного узла, как компонента сочетанной анестезии при оперативных вмешательствах по поводу врожденной каратаркты глаза у детей // Регионарная анестезия и лечение острой боли. - 2017. - Т. 11, № 3. - С. 202-207.

Oleschenko IG, Iureva TN, Zabolotsky DV, Gorbachev VI. (2017). Blockade of the pterygoid node as a component of combined anesthesia during surgical interventions for congenital eye cataract in children [Blokada krylonebnogo uzla, kak komponenta sochetannoy anestezii pri operativnykh vmeshatel'stvakh po povodu vrozhdennoy karatarkty glaza u detey]. Regionarnaya anesteziya i lechenie ostroy boli, 11 (3), 202-207.

4. Сенченко Н.Я., Нагаева К.А., Аюева Е.К., Юрьева Т.Н. Врожденная катаракта. Сообщение Современные представления об этиологии и принципах классификации. Обзор литературы // Офтальмология. - 2013. - № 4 (10). - С. 16-20.

Senchenko NYa, Nagaeva KA, Ayueva EK, Yuryeva TN. (2013). Congenital cataract. Modern ideas about the etiology and principles of classification. Review of the literature [Vrozhdennaya katarakta. Soobshchenie Sovremennye predstavleniya ob etiologii i printsipakh klassifikatsii. Obzor literatury]. Oftal'mologiya, 4 (10), 16-20.
5. Хватова А.В., Круглова Т.Б., Фильчикова Л.Н. Клинические особенности и патогенетические механизмы нарушения зрительных функций при врожденных катарактах // Зрительные функции и их коррекция у детей. - М.: Медицина, 2005. - С. 344-358.

Khvatova AV, Kruglova TB, Filchikova LN. (2005). Clinical features and pathogenetic mechanisms of visual function impairment in congenital cataracts [Klinicheskie osobennosti i patogeneticheskie mekhanizmy narusheniya zritel'nykh funktsiy pri vrozhdennykh kataraktakh]. Zritel'nye funktsii i ikh korrektsiya u detey. Moskva, 344358.

6. Щуко А.Г., Мищенко О.П., Сенченко Н.Я., Юрьева Т.Н. Факторы риска и осложнения, возникающие при поздних спонтанных дислокациях комплекса «заднекамерная ИоЛ капсульный мешок» в стекловидное тело // Офтальмохирургия. - 2017. - № 1. С. 21-26.

Shchuko AG, Mischenko OP, Senchenko NYa, Iureva TN. (2017). Risk factors and complications arising during late spontaneous dislocations of the "posterior chamber IOL capsular bag" into the vitreous humor [Faktory riska i oslozhneniya, voznikayushchie pri pozdnikh spontannykh dislokatsiyakh kompleksa «zadnekamernaya IOL kapsul'nyy meshok» v steklovidnoe telo]. Oftal'mokhirurgiya, (1), 21-26.

7. Acworth IN, McCabe DR, Maher TJ, Baskin S, Salem H. (eds.). (1997). The analysis of free radicals, their reaction products, and antioxidants, in oxidants, antioxidants and free radicals. Oxidants, Antioxidants, and Free Radicals. Washington (DC), 23-77.

8. Boone CH. (2017). Oxidative stress, metabolomics profiling, and mechanism of local anesthetic induced cell death in yeast. Redox Biol, 12, 139-149.

9. Cuzzocrea S, Riley D., Caputi AP, Saivemini D. (2001). Antioxidant therapy: a new pharmacological approach in shock, inflammation, ischemia/reperfusion injury. Pharmacol Rev, 53, 153-159.

10. Ebbeling MB, Oomen KP, de Ru JA, Hordijk GJ, Bleys RL. (2011) Neurochemical characterization of pterygopalatine ganglion branches in humans. Am J Rhinol Allergy, 25 (1), 50-53.

11. Gottschalk A, Sharma S, Ford J, Durieux ME, Tiouririne M. (2010). The role of the perioperative period in recurrence after cancer surgery. Anesth Analg, 110 (6), 1636-1643.

12. Kanigowska K. (2006). Influence of intraoperative complication on intraocular rigid lens fixation in pediatric cataract surgery. Klin Oczna, 108 (10-12), 401-404.

13. Khonsary SA, Ma Q, Villablanca P, Emerson J, Malkasian D. (2013). Clinical functional anatomy of the pterygopalatine ganglion, cephalgia and related dysautonomias: A review. Surg Neurol Int, 4 (Suppl 6), 422-S428.

14. Ledowski T. (2010). Monitoring of intra-operative nociception: skin conductance and surgical stress index versus stress hormone plasma levels. Anaesthesia, 65 (10), 1001-1006.

15. Ma F, Wang Q, Wang L. (2012). Advances in the management of the surgical complications for congenital cataract. Front Med, 6 (4), 360-365. 
16. Moreno-Montanes J, Sainz C, Maldonado MJ. (2003). Intraoperative and postoperative complications of Cionni endocapsular ring implantation.J Cataract Refract Surg, 29 (3), 492-497.

17. Rusu MC, Pop F. (2010). The anatomy of the sympathetic pathway through the pterygopalatine fossa in humans. Ann Anat, 192 (1), 17-22.
18. Speeg-Schatz C. (2011). Results and complications of surgery of congenital cataract. J Fr Ophthalmol, 34 (3), 203-207.

19. Volkova NV. Immunomodulatory therapy for keratitis complicated by corneal epithelial insufficiency. Available at: http://www.escrs.org/lisbon2017/programme/posters-details.asp?id=29053.

\section{Сведения об авторах}

Information about the authors

Олещенко Ирина Геннадьевна - врач отделения анестезиологии, Иркутский филиал ФГАУ МНТК «Микрохирургия глаза» имени акад. С.Н. Фёдорова» Минздрава России (664033, г. Иркутск, ул. Лермонтова, 337; тел. (3952) 56-41-13; е-таil: Iga. oleshenko@mail.ru) (1) http://orcid.org/0000-0003-1642-5276

Oleshchenko Irina Gennadievna - Anesthesiologist at the Unit of Anesthesiology, Irkutsk Branch of S. Fyodorov Eye Microsurgery Federal State Institution (664033, Irkutsk, ul. Lermontova, 337; tel. (3952) 56-41-13; e-mail: Iga.oleshenko@mail.ru) (1) http://orcid. org/0000-0003-1642-5276

Заболотский Дмитрий Владиславович - доктор медицинских наук, заведующий кафедрой анестезиологии, реаниматологии и неотложной педиатрии, ФГБОУ ВО «Санкт-Петербургский государственный педиатрический медицинский университет» Минздрава России (194100, г. Санкт-Петербург, ул. Литовская, 2; тел. (812) 591-79-11; e-mail: zdv4330303@ gmail.com)

Zabolotsky Dmitriy Vladislavovich - Doctor of Medical Sciences. Head of the Department of Anesthesiology, Intensive Care and Emergency Medicine, Saint Petersburg State Pediatric Medical University (194100, Saint Petersburg, ul. Litovskaya, 2; tel. (812) 591-79-11; e-mail: zdv4330303@gmail.com)

Юрьева Татьяна Николаевна - доктор медицинских наук, профессор, заместитель директора по научной работе, Иркутский филиал ФГАУ МНТК «Микрохирургия глаза» имени акад. С.Н. Фёдорова» Минздрава России; профессор кафедры глазных болезней, Иркутская государственная медицинская академия последипломного образования - филиал ФГБоу ДПО «Российская медицинская академия непрерывного профессионального образования» Минздрава России (е-mail: tnyurieva@ mail.ru) (1) http://orcid.org/0000-0003-0547-7521

Yureva Tatyana Nikolaevna - Doctor of Medical Sciences, Professor, Deputy Director for Science, Irkutsk Branch of S. Fyodorov Eye Microsurgery Federal State Institution; Professor at the Department of Eye Diseases, Irkutsk State Medical Academy of Postgraduate Education - Branch Campus of the Russian Medical Academy of Continuing Professional Education (e-mail: tnyurieva@ mail.ru) (1) http://orcid.org/0000-0003-0547-7521

Сенченко Надежда Яковлевна - офтальмохирург, заведующая хирургическим отделением, Иркутский филиал ФГАУ МНТК «Микрохирургия глаза» имени акад. С.Н. Фёдорова» Минздрава России (e-mail: nadezhdasenchenko@gmail.com) 이라:// orcid.org/0000-0003-0608-8376

Senchenko Nadezhda Yakovlevna - Ophthalmic Surgeon, Head of the Surgical Unit, Irkutsk Branch of S. Fyodorov Eye Microsurgery Federal State Institution (e-mail: nadezhdasenchenko@gmail.com) (1) http://orcid.org/0000-0003-0608-8376

Шантурова Марина Анатольевна - офтальмохирург, заведующая хирургическим отделением, Иркутский филиал ФГАУ МНТК «Микрохирургия глаза» имени акад. С.Н. Фёдорова» Минздрава России (e-mail: shanturovam@mail.ru) (1 http://orcid. org/0000-0002-3620-2777

Shanturova Marina Anatolyevna - Ophthalmic Surgeon, Head of the Surgical Unit, Irkutsk Branch of S. Fyodorov Eye Microsurgery Federal State Institution (e-mail: shanturovam@mail.ru) @ http://orcid.org/0000-0002-3620-2777 